\title{
Peptide nucleic acids targeting $\beta$-globin mRNAs selectively inhibit hemoglobin production in murine erythroleukemia cells
}

\author{
GIULIA MONTAGNER ${ }^{1}$, CHIARA GEMMO ${ }^{1}$, ENRICA FABBRI $^{1}$, ALEX MANICARDI $^{2}$, IGEA ACCARDO $^{2}$, \\ NICOLETTA BIANCHI ${ }^{1}$, ALESSIA FINOTTI ${ }^{1}$, GIULIA BREVEGLIERI ${ }^{1}$, FRANCESCA SALVATORI ${ }^{1}$, \\ MONICA BORGATTI ${ }^{1}$, ILARIA LAMPRONTI ${ }^{1}$, ALBERTO BRESCIANI ${ }^{3}$, SERGIO ALTAMURA ${ }^{3}$, \\ ROBERTO CORRADINI ${ }^{2}$ and ROBERTO GAMBARI ${ }^{1}$
}

\author{
${ }^{1}$ Department of Life Sciences and Biotechnology, University of Ferrara, Ferrara; ${ }^{2}$ Department of Chemistry, \\ University of Parma, Parma; ${ }^{3}$ IRBM Science Park, Pomezia (RM), Italy
}

Received July 8, 2014; Accepted October 3, 2014

DOI: $10.3892 / \mathrm{ijmm} .2014 .2005$

\begin{abstract}
In the treatment of hemoglobinopathies, amending altered hemoglobins and/or globins produced in excess is an important part of therapeutic strategies and the selective inhibition of globin production may be clinically beneficial. Therefore the development of drug-based methods for the selective inhibition of globin accumulation is required. In this study, we employed peptide nucleic acids (PNAs) to alter globin gene expression. The main conclusion of the present study was that PNAs designed to target adult murine $\beta$-globin mRNA inhibit hemoglobin accumulation and erythroid differentiation of murine erythroleukemia (MEL) cells with high efficiency and fair selectivity. No major effects were observed on cell proliferation. Our study supports the concept that PNAs may be used to target mRNAs that, similar to globin mRNAs, are expressed at very high levels in differentiating erythroid cells. Our data suggest that PNAs inhibit the excess production of globins involved in the pathophysiology of hemoglobinopathies.
\end{abstract}

\section{Introduction}

The majority of the molecular biology based approaches developed for the experimental therapy of thalassemia and sickle-cell anemia (SCA) are based on the induction of defective globin ( $\beta$-globin in $\beta$-thalassemia) (1-5) or (also in association with this strategy) the induction of fetal hemoglobin (HbF) (6-10). The de novo production of adult hemoglobin ( $\mathrm{HbA})$ can be achieved in $\beta^{0}$-thalassemias by gene therapy (1-4) and gene

Correspondence to: Professor Roberto Gambari, Department of Life Sciences and Biotechnology, University of Ferrara, Via Fossato di Mortara 74, I-44121 Ferrara, Italy

E-mail: gam@unife.it

Key words: peptide nucleic acids, sickle-cell anemia, $\beta$-globin, hemoglobin, erythroid differentiation correction, by homologous recombination $(11,12)$ and/or by the treatment of erythroid cells with molecules causing read-through (13). The induction of $\mathrm{HbF}$ can be obtained by using low molecular weight drugs causing the induction of the $\gamma$-globin gene $(6-8,14-17)$, artificial promoters $(18,19)$, decoy molecules targeting transcription factors involved in the transcriptional repression of $\gamma$-globin genes (MYB, KLF-1 and BCL-11A) $(20,21)$, or microRNAs targeting mRNAs coding for these repressors (data are available for microRNAs miR-15a, miR-16-1, miR-486-3p and miR-23a/27a) (22-24). On the other hand, clinical complications in SCA and $\beta$-thalassemia are also related to the production of defective proteins ( $\beta$-globin in SCA) (25-27) or to the accumulation of free globins which are not organized in a functional tetramer (such as in the case of free $\alpha$-globins in $\beta$-thalassemia) $(28,29)$. It is well known that sickle hemoglobin $(\mathrm{HbS})$ has peculiar biochemical properties, leading to polymerization when deoxygenated. HbS polymerization is associated with a reduction in cell ions and water content (cell dehydration) and increased red cell density, which further accelerates $\mathrm{HbS}$ polymerization. Pathophysiological studies have indicated that the dense, dehydrated red cells may play a central role in acute and chronic clinical manifestations of sickle-cell disease, in which intravascular sickling in capillaries and small vessels leads to vaso-occlusion and impaired blood flow in a variety of organs and tissues (30). Therefore, the development of drug-based methods for the inhibition of the accumulation of defective hemoglobins ( $\mathrm{HbS}$ in SCA) or globin produced in excess ( $\alpha$-globins in $\beta$-thalassemia) is required $(31,32)$.

In this field of investigation, peptide nucleic acids (PNAs) may be of great interest (33). PNAs are DNA analogues in which the sugarphosphate backbone is replaced by $\mathrm{N}$-(2-aminoethyl) glycine units (33). These very interesting molecules were described for the first time by Nielsen et al (34) and, despite a radical structural change with respect to DNA and RNA, they are capable of sequence-specific and efficient hybridization with complementary DNA and RNA, forming Watson-Crick double helices (35). In addition, they are able to generate triple helix formation with double-stranded DNA and perform 
strand invasion (34). Accordingly, PNA-based analogues have been proposed as antisense molecules targeting mRNAs and microRNAs, triple-helix forming molecules targeting eukaryotic gene promoters, artificial promoters and decoy molecules targeting transcription factors (36). To the best of our knowledge, PNAs have not yet been employed to inhibit the expression of globin genes in erythroid cells. Thus, the aim of this study was to verify whether PNAs targeting globin mRNAs can be used to modulate globin gene expression and to reduce the level of a given type of globin. For this purpose, we produced one PNA targeting murine adult $\beta$-globin mRNAs and another recognizing the human $\gamma$-globin and $\beta$-globin mRNAs. These PNAs were tested on relevant target erythroid cell lines, such as the murine erythroleukemia (MEL) cell line. Erythroid differentiation and the high production of hemoglobins were induced by treatment with dimethylsulfoxide (DMSO) and hexamethylene bisacetamide (HMBA) (37-39).

\section{Materials and methods}

Synthesis and characterization of PNAs. The synthesis of the two PNAs was performed using standard automated Fmocbased chemistry with HBTU/DIPEA coupling on a ChemMatrix resin loaded with Fmoc-Gly-OH as first monomer (loading $0.2 \mathrm{mmol} / \mathrm{g}, 5 \mu \mathrm{mol}$ scale), on a Syro II peptide synthesizer, using commercially available monomers (Link Technologies, Bellshill, UK); Fmoc-Arg (Pbf)-OH (Sigma-Aldrich, St. Louis, MO, USA) was used for octaarginine synthesis. PNA purification was performed by reversed-phase high-performance liquid chromatography (RP-HPLC) with UV detection at $260 \mathrm{~nm}$ using a semi-prep column C18 $(10 \mu \mathrm{m}, 300 \times 7.7 \mathrm{~mm}$, Xterra Waters, $300 \AA$ ), eluting with water containing $0.1 \%$ TFA (eluent A) and acetonitrile containing 0.1\% TFA (eluent B); elution gradient: from $100 \%$ A to $50 \%$ B in 30 min, flow: $4 \mathrm{ml} / \mathrm{min}$. The purity and identity of the purified PNA were examined by ultra-performance liquid chromatography tandem mass-spectrometry (UPLC-MS; Waters Acquity equipped with ESI-Q analizer) using an Acquity UPLC BEH C18; 2.1x50 MM, $1.7 \mu \mathrm{m}$ column. Anti-M- $\beta$ glob-PNA: yield, 6\%; electrospray ionization mass spectrometry (ESI-MS): $\mathrm{m} / \mathrm{z}$ found (calculated): 1267.3 (1267.3) $\left[\mathrm{MH}_{5}{ }^{5+}\right], 1056.2$ (1056.2) $\left[\mathrm{MH}_{6}{ }^{6+}\right], 905.4(905.5)\left[\mathrm{MH}_{7}{ }^{7+}\right], 792.2(792.4)\left[\mathrm{MH}_{8}{ }^{8+}\right], 704.5$ (704.5) $\left[\mathrm{MH}_{9}{ }^{9+}\right]$; calculated MW: 6331.39. Anti-H- $\gamma$ glob-PNA: yield: $8 \%$; ESI-MS: m/z found (calculated): 1346.0 (1345.4) $\left[\mathrm{MH}_{4}{ }^{4+}\right] ; 1076.8(1076.5)\left[\mathrm{MH}_{5}{ }^{5+}\right], 897.7$ (897.3) $\left[\mathrm{MH}_{6}{ }^{6+}\right], 769.5$ (769.2) $\left[\mathrm{MH}_{7}{ }^{7+}\right], 673.3(673.2)\left[\mathrm{MH}_{8}{ }^{8+}\right], 598.8(598.5)\left[\mathrm{MH}_{9}{ }^{9+}\right]$, 539.0 (538.8) $\left[\mathrm{MH}_{10}{ }^{10+}\right]$; calculated MW: 5377.54 .

MEL and K562 cell lines and culture conditions. MEL cells (37-39) were cultured in humidified atmosphere of $5 \% \mathrm{CO}_{2} /$ air in RPMI-1640 medium (Sigma-Aldrich) supplemented with $10 \%$ fetal bovine serum (FBS; Biowest, Nuaillé, France), $50 \mathrm{U} / \mathrm{ml}$ penicillin and $50 \mu \mathrm{g} / \mathrm{ml}$ streptomycin (39). DMSO and HMBA were from Sigma-Aldrich. Stock solutions of HMBA were stored at $-20^{\circ} \mathrm{C}$ in the dark and diluted immediately before use. Treatment of the MEL cells with HMBA and DMSO was carried out by adding the appropriate drug concentrations at the beginning of the cultures $(30,000$ cells/ $\mathrm{ml}$ were seeded). To determine the effects of the treatments on the proliferation of the MEL cells, cell growth was monitored by determining the cell number/ml using a Z1 Coulter Counter (Coulter Electronics, Hialeah, FL, USA). Erythroid differentiated MEL cells containing hemoglobin were detected by specific reaction with a benzidine/hydrogen peroxide solution $\left(0.2 \%\right.$ in $5 \mathrm{M}$ glacial acetic acid and $10 \% \mathrm{H}_{2} \mathrm{O}_{2}$ ). The K562-D5 cell line was employed as it produces, in addition to hemoglobin $(\mathrm{Hb})$ Gowerl and hemoglobin $(\mathrm{Hb})$ Portland, HbF and $\operatorname{HbA}(40)$.

RNA extraction. The cells were isolated by centrifugation at $1,500 \mathrm{rpm}$ for $10 \mathrm{~min}$ at $4^{\circ} \mathrm{C}$, washed with phosphate-buffered saline (PBS) and lysed with TRI-reagent ${ }^{\mathrm{TM}}$ (Sigma-Aldrich) according to the manufacturer's instructions. The isolated RNA was washed once with cold $75 \%$ ethanol, dried and dissolved in nuclease-free pure water prior to use.

Quantitative reverse transcription polymerase chain reaction (RT-qPCR). For gene expression analysis, $500 \mathrm{ng}$ of total RNA were reverse transcribed using random hexamers. Quantitative PCR assays were carried out using gene-specific double-quenched probes containing a 5'-FAM fluorophore, a 3'-IBFQ quencher and an internal ZEN quencher. The nucleotide sequences used for the RT-qPCR analysis of mouse globin mRNAs were $\alpha$-globin forward, 5'-CTG ACC TCC AAG TAC CGT TAA G-3' and reverse primer, 5'-GCT TCT TCC TAC TCA GGC TTT AT-3' and $\alpha$-globin probe, 5'-/56-FAM/TCT CTC CCT/ZEN/TGC ACC TGT ACC TCT/3IABkFQ/-3'; $\beta$-globin forward, 5'-GGA AAG GTG AAC TCC GAT GAA-3' and reverse primer, 5'-TGA TAG CAG AGG CAG AGG ATA G-3' and $\beta$-globin probe, 5'-/56-FAM/CCT TGG ACC/ZEN/ CAG CGG TAC TTT GAT/3IABkFQ/-3'. The primers and probes used to assay mouse globins were purchased from Integrated DNA Technologies (IDT; Coralville, IA, USA). The relative expression was calculated using the comparative cycle threshold method and the endogenous control mouse gene, GAPDH, was used as a reference gene (PrimeTime Mm.PT.39a.1, IDT).

HPLC analysis. The cells were harvested, washed once with PBS and the pellets were lysed in lysis buffer (sodium dodecyl sulphate $0.01 \%$ ). After spinning for $1 \mathrm{~min}$ in a microcentrifuge, the supernatant was collected and stored at $4^{\circ} \mathrm{C}$. Hemoglobins in the lysates were separated by cation-exchange HPLC (Pharmacia LKB Gradient Pump 2249, VWM 2141), using a Synchropak CM300 (250x4.6 mm) column (Eichrom Technologies, Inc., Darien, IL, USA) and BisTris (30 mM) buffer. Standard HbA and HbF (Sigma-Aldrich, Milwaukee, WI, USA; Helena Laboratories, Beaumont, TX, USA) solutions were used as a reference.

Bioinformatics analysis. The secondary structure of the mouse $\beta^{\text {major }}$ - and $\beta^{\text {minor }}$-globin mRNA sequences, $5^{\prime}$ untranslated region (UTR), coding sequence (CDS) and 3'UTR, was predicted using the program available online TBI ViennaRNA Web Services (http://rna.tbi.univie.ac.at). The mouse $\beta$-globin reference sequences analyzed were obtained from the NCBI website.

Statistical analysis. The results are expressed as the means \pm standard error of the mean (SEM). Comparisons 


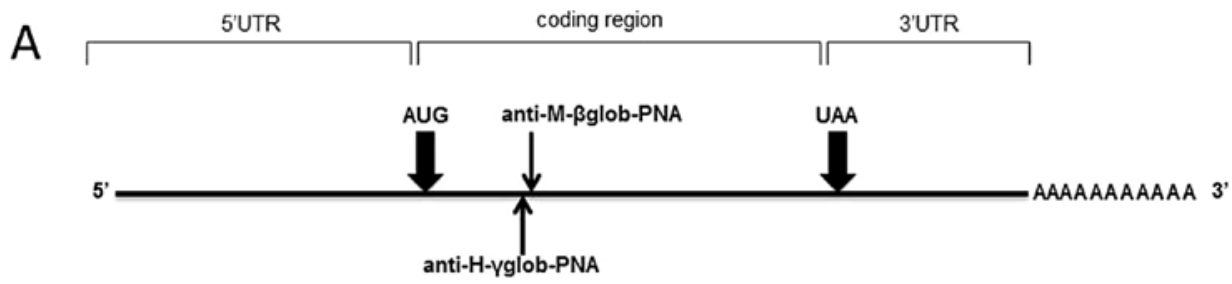

\begin{tabular}{|c|c|c|c|c|c|c|}
\hline \multirow[t]{2}{*}{ PNA } & \multirow[t]{2}{*}{ Sequence } & \multicolumn{5}{|c|}{ Complementarity with potential globin mRNA targets } \\
\hline & & $\begin{array}{c}\text { Mouse } \\
\beta_{\text {major }}\end{array}$ & $\begin{array}{c}\text { Mouse } \\
\beta^{\text {minor }}\end{array}$ & Human $\varepsilon$ & Human $\gamma$ & Human $\beta$ \\
\hline anti-M-ßglob-PNA & H-R $\mathrm{R}_{8}$-GAG GCA GAG GAT AGG TCT-Gly-NH ${ }_{2}$ & $18 / 18$ & $18 / 18$ & $14 / 18$ & $15 / 18$ & $10 / 18$ \\
\hline anti-H-yglob-PNA & $\mathrm{H}-\mathrm{R}_{8}$-TCG CAA AGC TGT CAA -Gly-NH ${ }_{2}$ & $12 / 15$ & $12 / 15$ & $14 / 15$ & $15 / 15$ & $10 / 15$ \\
\hline
\end{tabular}
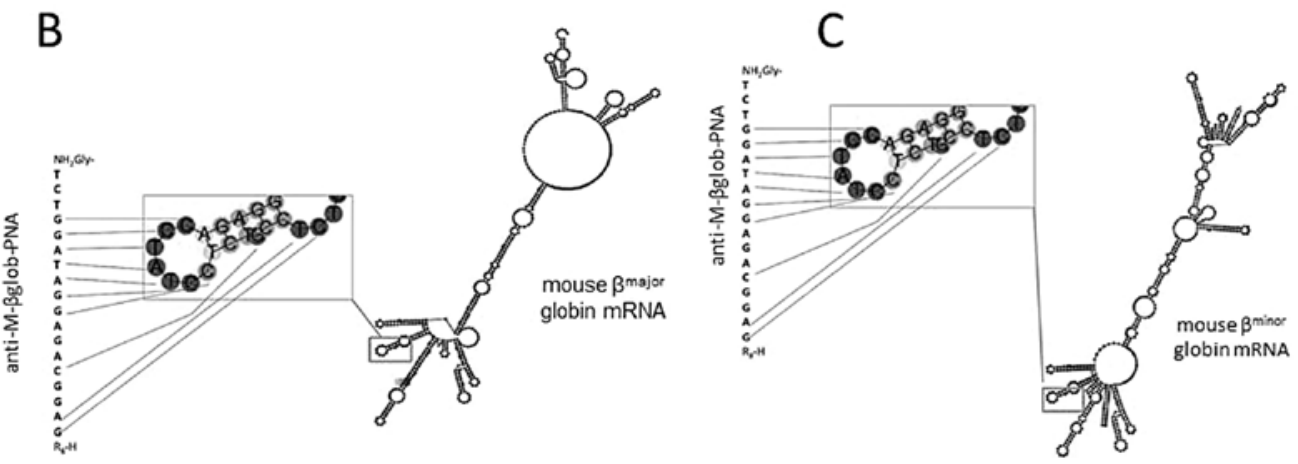

Figure 1. (A) Location of the binding sites (upper panel) and sequences of the PNAs employed in our study (lower panel). (B and C) Possible interactions between anti-M- $\beta$ glob-PNA and mouse (B) $\beta^{\text {major }}$ and (C) $\beta^{\text {minor }}$ globin mRNAs. Predicted secondary structure of the 5'UTR, CDS and 3'UTR region of mouse $\beta^{\text {major }}$ - and $\beta^{\text {minor }}$-globin mRNAs were based on the NCBI website references sequences, NM_001278161.1 and NM_016956.3, respectively and obtained using the TBI ViennaRNA Web Services (http://rna.tbi.univie.ac.at/). Magnification of the central portion of the CDS site of the globins points out the possible interaction between the $\beta$-globin CDS target strands and the anti-M- $\beta$ glob-PNA region. PNA, peptide nucleic acid.

between groups were made using a paired Student's t-test and one-way analysis of variance (ANOVA). Statistical significance was defined with $\mathrm{p}<0.01$.

\section{Results}

Design of PNAs. The location of the binding sites and the sequences of the PNAs employed in this study are presented in Fig. 1 . As clearly appreciable from the analysis of the sequences recognized, the anti-M- $\beta$ glob-PNA is able to hybridize to a region of both mouse $\beta^{\text {major }}$ - and $\beta^{\text {minor }}$-globin mRNAs exhibiting similar predicted secondary structures (Fig. 1B and C). This feature allows us to study the effects of the PNAs simply analyzing the proportion of erythroid differentiated MEL cells.

These cells, upon the induction of erythroid differentiation with HMBA or DMSO produce almost exclusively $\mathrm{Hb}^{\text {major }}$ $\left(\alpha_{2} \beta_{2}{ }^{\text {major }}\right)$ and $\mathrm{Hb}^{\text {minor }}\left(\alpha_{2} \beta_{2}{ }^{\text {minor }}\right)$. Moreover, these PNAs display 4 to 8 mismatches with human $\beta$-globin ( 8 mismatches), $\gamma$-globin (3 mismatches) and $\varepsilon$-globin (4 mismatches) (Fig. 1A, bottom panel). This allows us to verify possible non-specific inhibitory effects when used on K562 cell clones subjected to erythroid differentiation which produce, upon treatment with mithramycin (MTH), high levels of Hb Gower $1\left(\zeta_{2} \varepsilon_{2}\right)$, $\mathrm{Hb}$ Portland $\left(\zeta_{2} \gamma_{2}\right), \operatorname{HbF}\left(\alpha_{2} \gamma_{2}\right)$ and $\mathrm{HbA}\left(\alpha_{2} \beta_{2}\right)(40)$. Conversely, as control PNA molecules we used anti-H- $\gamma$ glob-PNA recognizing the evolutionarily homologue human $\gamma$-globin mRNAs and displaying 3 mismatches with the murine $\beta^{\text {major }}$ and $\beta^{\text {minor }}$ mRNAs (Fig. 1A). Both anti-M- $\beta$ glob-PNA and anti-H- $\gamma$ glob-PNA were linked with a $\mathrm{R}_{8}$ polyarginine peptide, since it has been reported in several studies that the uptake of PNAs by target cells is difficult $(41,42)$. $\mathrm{R}_{8}$ was employed in order to maximize PNA uptake, as reported by our group for several PNAs, which, without exception, are internalized with very high efficiency to target cells (43-45).

Effects of anti-M- $\beta$ glob-PNA on the growth of MEL cells. Fig. 2 shows the kinetics of differentiation (Fig. 2A) and cell growth (Fig. 2B) obtained when the MEL cells are treated with $2 \%$ and $2.5 \mathrm{mM}$ DMSO and HMBA, respectively. The high level of induction ( $>80 \%$ after 3 or 4 days in all the experiments performed) confirms that this cellular system is excellent to determine inhibitors of the expression of adult $\beta$-globin genes, since, unlike other erythroid cellular model systems (such as human K562 cells), these cells mostly produce the adult-type $\mathrm{Hb}^{\text {major }}$ and $\mathrm{Hb}^{\text {minor }}$ hemoglobins (39). As shown in Fig. $2 \mathrm{C}$, the addition of anti-M- $\beta$ glob-PNA did not alter the proliferation rate of these cells, formally demonstrating no cytotoxic effects of this PNA on the MEL cells, either in the absence of differentiation inducers (data not shown) or in the presence of DMSO or HMBA.

Anti-M- $\beta$ glob-PNA inhibits the erythroid differentiation of MEL cells induced by DMSO and HMBA. The effects of antiM- $\beta$ glob-PNA on the erythroid differentiation of MEL cells were first analyzed by benzidine staining of the treated cells. The results of this experiment are presented in Fig. 3, which clearly illustrates that the MEL cells treated with DMSO (Fig. 3G and H) and HMBA (Fig. 3C and D) do not efficiently

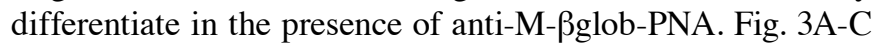



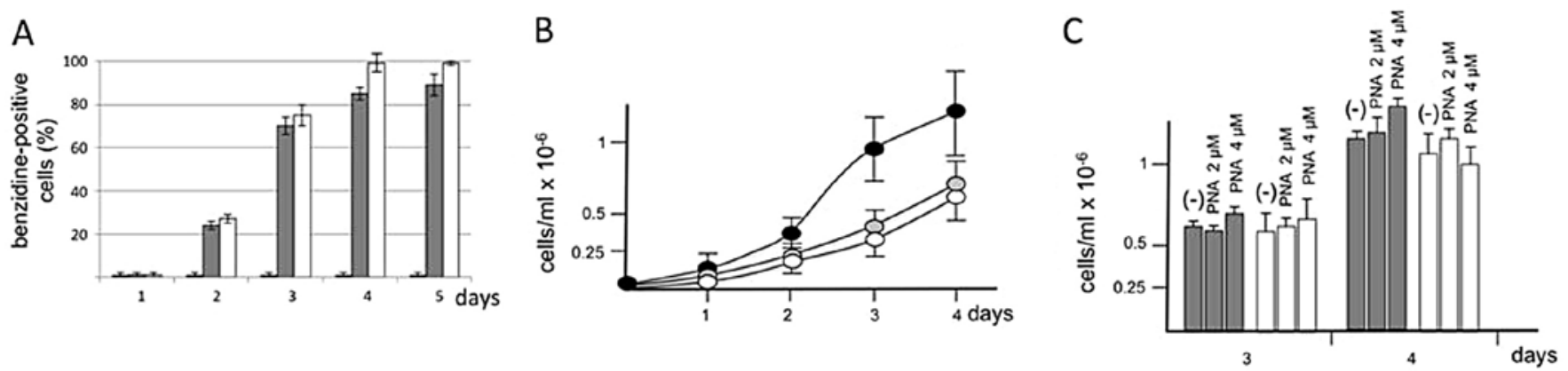

Figure 2. (A) Level of erythroid differentiation obtained when murine erythroleukemia (MEL) cells are treated with 2\% dimethylsulfoxide (DMSO) (grey boxes), or with $2.5 \mathrm{mM}$ hexamethylene bisacetamide (HMBA) (white boxes). Untreated cells, black boxes. (B) Proliferation of MEL cells cultured without inducers (black symbols), or in the presence of 2\% DMSO (grey symbols), or $2.5 \mathrm{mM} \mathrm{HMBA}$ (white symbols). (C) Effects of 2 and $4 \mu \mathrm{M}$ of anti-M- $\beta$ glob-PNA on the proliferation of MEL cells treated with 2\% DMSO (grey boxes), or with 2.5 mM HMBA (white boxes). PNA, peptide nucleic acid.

A

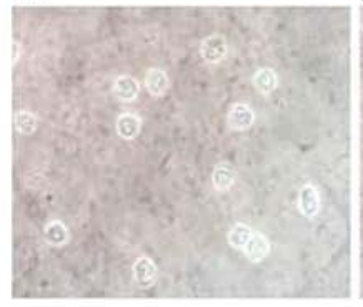

B

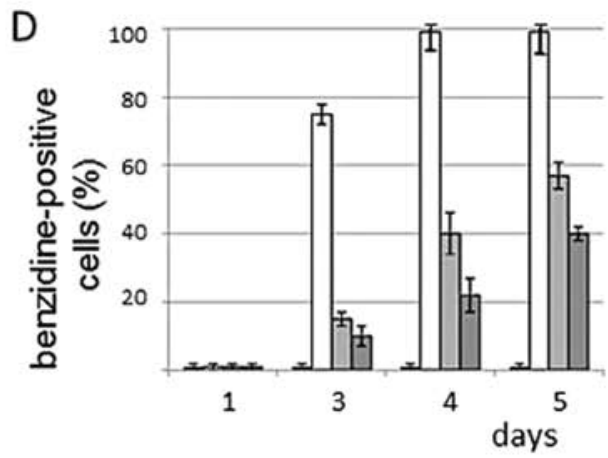

C

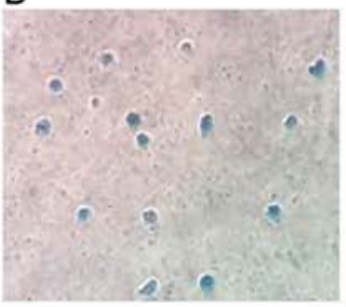

$\mathrm{F}$
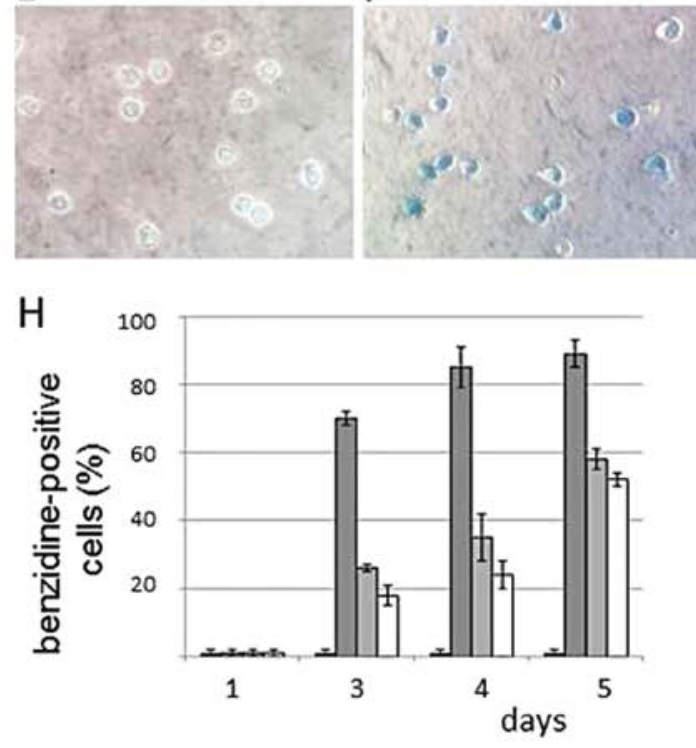

G

$(-)$

HMBA

HMBA

$+2 \mu \mathrm{M}$ anti-M-Bglob-PNA

HMBA

$+4 \mu \mathrm{M}$ anti-M-Bglob-PNA

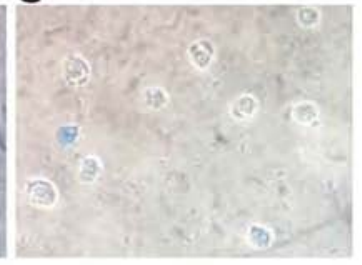

$(-)$

DMSO

DMSO

$+2 \mu \mathrm{M}$ anti-M-Bglob-PNA

DMSO $\square$

$+4 \mu \mathrm{M}$ anti-M-Bglob-PNA

Figure 3. Effects of anti-M- $\beta$ glob-PNA on erythroid differentiation of murine erythroleukemia (MEL) cells induced by (A-D) hexamethylene bisacetamide (HMBA) or (E-H) dimethylsulfoxide (DMSO). Intracellular accumulation of hemoglobin was determined by the benzidine staining of treated cells (A-C and E-G) Representative examples of benzidine staining of (A and E) untreated cells, or cells treated with (B) HMBA, (C) HMBA plus $4 \mu \mathrm{M}$ anti-

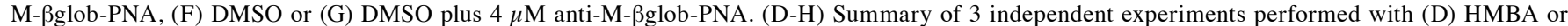
(H) DMSO without the addition of the PNA or in the presence of the indicated concentrations of anti-M- $\beta$ glob-PNA. PNA, peptide nucleic acid. 

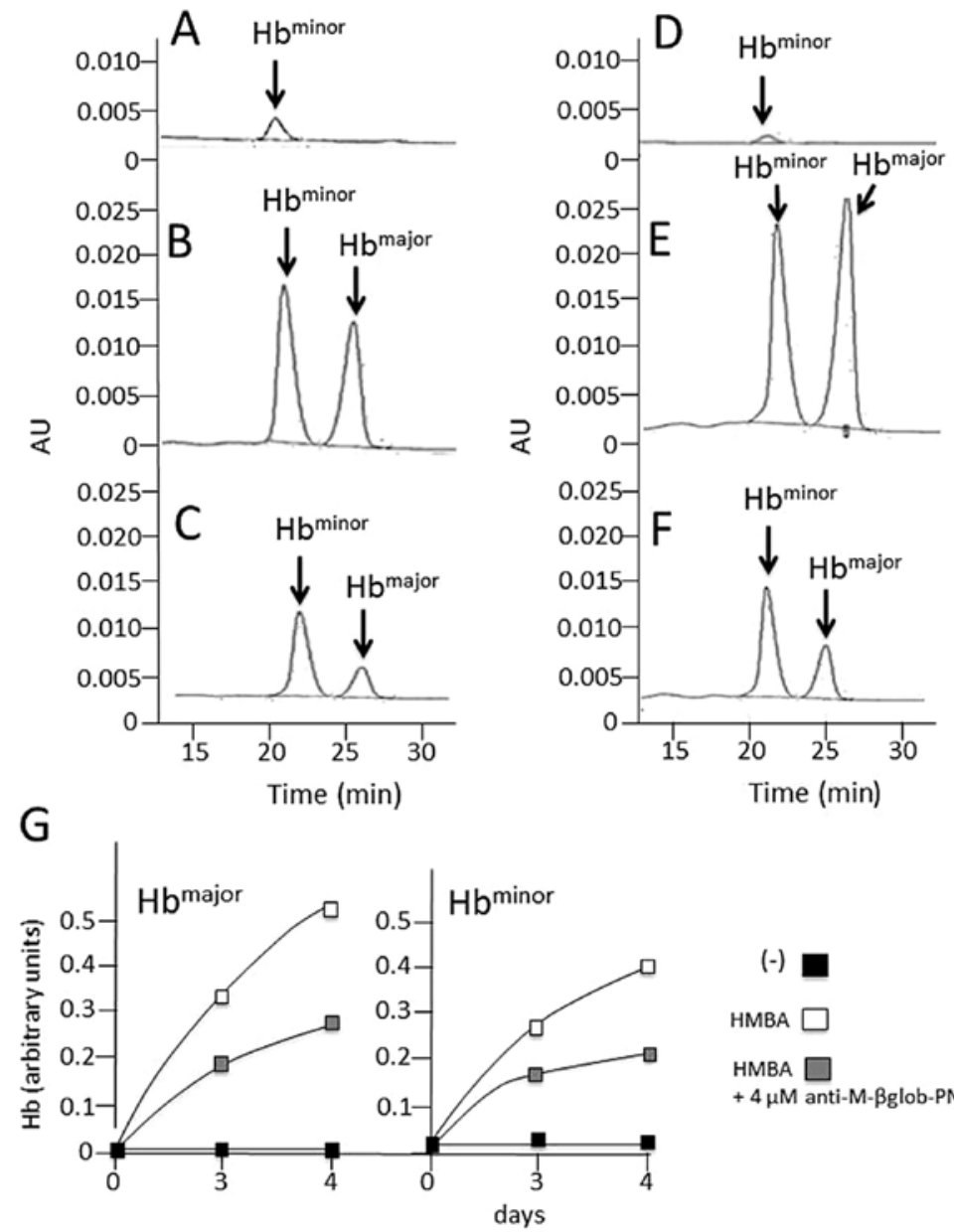

\section{$(-)$}

HMBA $\square$

HMBA $\square$

$+4 \mu \mathrm{M}$ anti-M-Bglob-PNA

Figure 4. Effects of anti-M- $\beta$ glob-PNA on hemoglobin accumulation. Representative HPLC analysis of (A and D) untreated murine erythroleukemia (MEL) cells, (B and E) hexamethylene bisacetamide (HMBA)-treated cells or (C and F) cells treated with HMBA in the presence of $4 \mu \mathrm{M}$ anti-M- $\beta \mathrm{glob}-\mathrm{PNA}$; (A-C) 3 days of treatment and (D-F) 4 days of treatment. (G) Quantitative analyses of $\mathrm{Hb}^{\text {major }}$ and $\mathrm{Hb}^{\text {minor }}$. PNA, peptide nucleic acid.

and E-G shows representative experiments, while Fig. 3D and $\mathrm{H}$ shows the summary of 3 independent experiments, confirming a decrease in the proportion of benzidine-positive (hemoglobin-containing) PNA-treated cells.

Effects of anti-M- $\beta$ glob-PNA on hemoglobin and $\beta$-globin mRNA accumulation in MEL cells treated with HMBA. The effects of anti-M- $\beta$ glob-PNA on hemoglobin and $\beta$-globin mRNA accumulation were examined in the HMBA-treated cells by HPLC (for hemoglobin analysis) and RT-qPCR (for the analysis of $\beta$-globin mRNA). The results are presented in Fig. 4, which clearly illustrates that anti-M- $\beta$ glob-PNA inhibited the accumulation of both $\mathrm{Hb}^{\text {major }}$ and $\mathrm{Hb}^{\text {minor }}$ hemoglobins fully in agreement with the data shown in Fig. 3. Of note, anti-M- $\beta$ glob-PNA also inhibited, to a certain extent, $\beta$-globin mRNA, suggesting that the inhibition of hemoglobin production may be also associated with the lower stability of $\beta$-globin mRNA (data not shown).

Specificity of the effects of anti-M- $\beta$ glob-PNA. The effects of antiM- $\beta$ glob-PNA on erythroid differentiation were also examined using human K562 cells subjected to erythroid differentiation by treatment with mithramycin (MTH). As shown in Fig. 5 no inhibitory effects of anti-M- $\beta$ glob-PNA were observed on the
MTH-stimulated K562-D5 cell clones, indicating high levels of specificity of the inhibitory effects of the anti-M- $\beta$ glob-PNA. Furthermore, control experiments were also performed using the anti-H- $\gamma$ glob-PNA on HMBA- and DMSO-treated MEL cells. Of note, no inhibitory effects were observed using the anti-H- $\gamma$ glob-PNA, suggesting that the effects of treatment of the erythroid cells with PNAs were sequence-specific (Fig. 6).

\section{Discussion}

In the treatment of SCA, $\mathrm{HbS}$ appears to be an important therapeutic target, since its polymerization is responsible for the sickling of SCA red-blood cells and important adverse clinical parameters (25-27). For instance, intravascular sickling in capillaries and small vessels leads to vaso-occlusion and impaired blood flow in a variety of organs and tissues (30). These conclusions are sustained by strong evidence suggesting that the induction of $\mathrm{HbF}$ following the treatment of SCA patients with hydroxyurea (HU) appears to be beneficial, due to the intrinsic anti-sickling properties of $\mathrm{HbF}(46,47)$. In any case, the inhibition of $\beta$-globin may be beneficial, allowing further reduction of sickling properties. Therefore the proof-of-principle of PNA-based methods enabling the effective inhibition of the accumulation of $\beta$-globin is of interest and of potential biomedical application. 

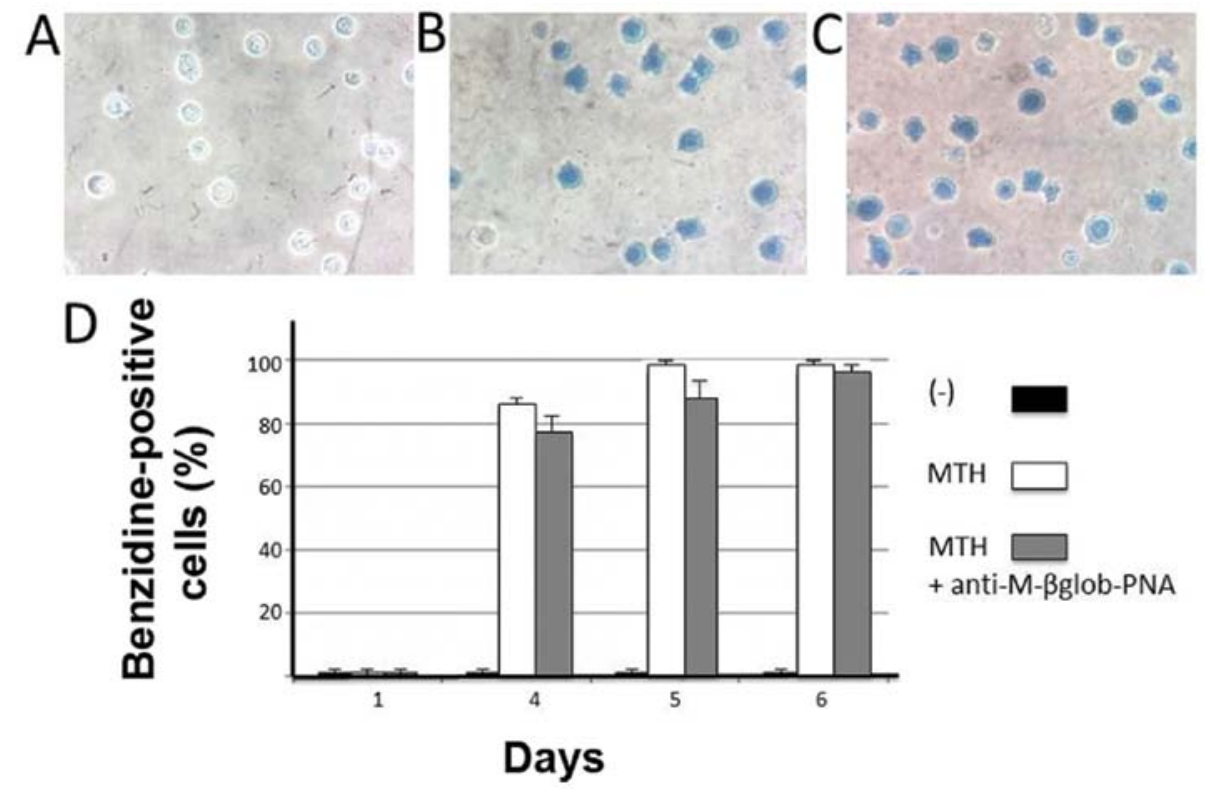

$(-)$

MTH

MTH

+ anti-M-Bglob-PNA

Figure 5. Lack of effects of anti-M- $\beta$ glob-PNA on erythroid differentiation of K562-D5 cells induced by mithramycin (MTH). Intracellular accumulation of hemoglobin was determined by benzidine staining. (A-C) Representative examples of benzidine staining of (A) untreated K562-D5 cells, or cells treated for 4 days with (B) MTH or (C) MTH plus $4 \mu \mathrm{M}$ anti-M-Bglob-PNA. (D) Summary of 3 independent experiments. The proportion of benzidine-positive cells was determined at the beginning of the treatment (day 1) and after 4, 5 and 6 days of cell culture without treatment (black boxes), or treatment with MTH $20 \mathrm{nM}$ in the absence (white box) or in the presence (grey boxes) of $4 \mu \mathrm{M}$ anti-M- $\beta$ glob-PNA. PNA, peptide nucleic acid.
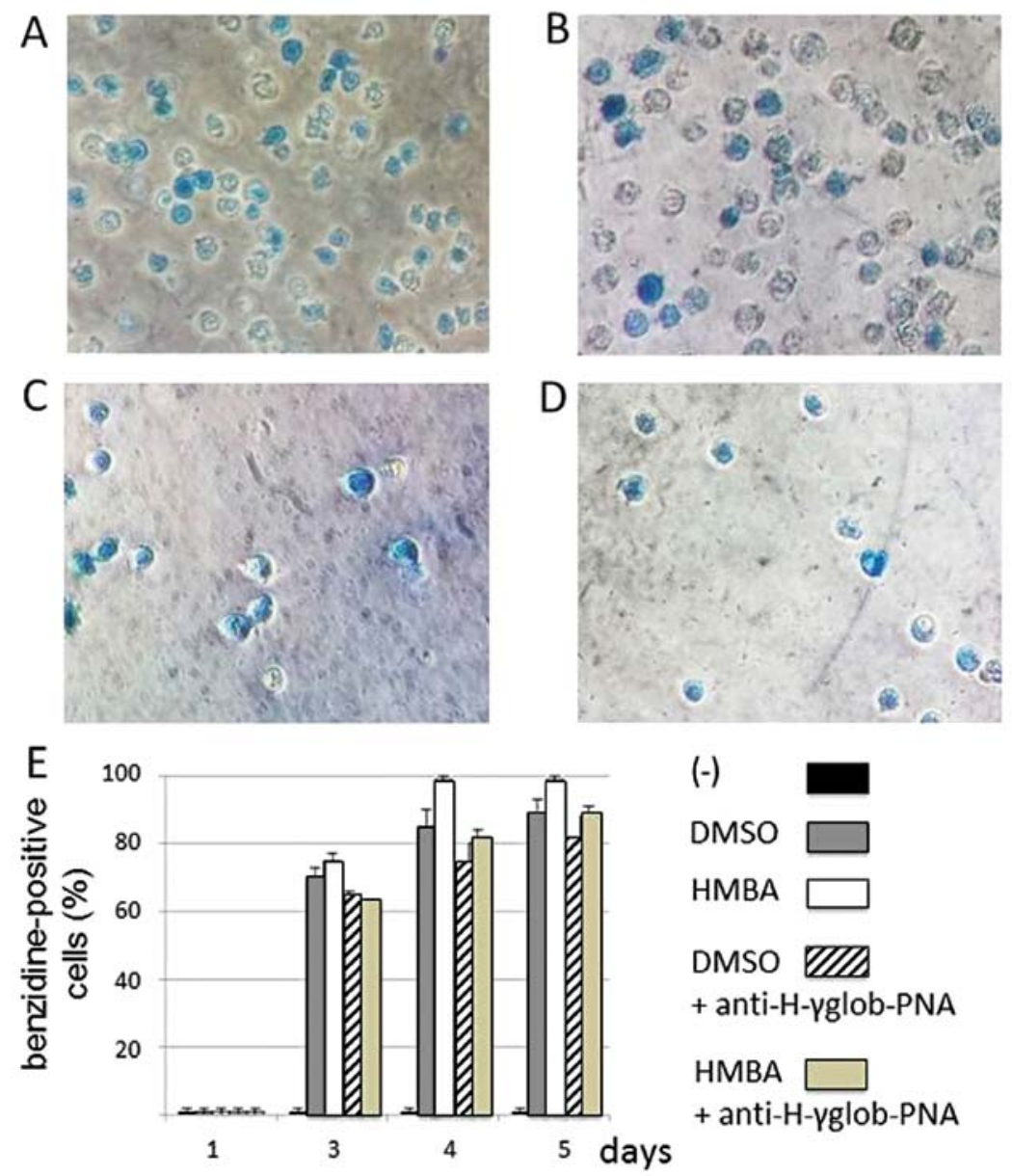

Figure 6. Lack of effects of anti-H- $\gamma$ glob-PNA on erythroid differentiation of murine erythroleukemia (MEL) cells induced by dimethylsulfoxide (DMSO) or hexamethylene bisacetamide (HMBA). Intracellular accumulation of hemoglobin was determined by benzidine staining. (A-D) Representative examples of benzidine staining of MEL cells treated for 3 days with (A and B) $2 \%$ DMSO or (C and D) 2.5 mM HMBA (A and C) in the absence or (B and D) in the presence of $4 \mu \mathrm{M}$ anti-H- $\gamma$ glob-PNA. (E) Summary of 3 independent experiments. The proportion of benzidine-positive cells was determined at the beginning of the treatment (day 1) and after 3, 4 and 5 days of cell culture performed as described in the index. PNA, peptide nucleic acid. 


\section{Acknowledgements}

This study was supported by a grant from the Italian Ministry of University and Research (MIUR) and from TOP-THAL (R\&S project for PMI Lazio-Cup code F57I12000010007). R.G. received a grant from Fondazione Cariparo (Cassa di Risparmio di Padova e Rovigo), CIB, from UE FP7 THALAMOSS Project (THALAssaemia Modular Stratification System for personalized therapy of $\beta$-thalassemia; 306201), from Telethon GGP10124 and from AIRC IG13575. This study was also supported by Associazione Veneta per la Lotta alla Talassemia (AVLT), Rovigo.

\section{References}

1. Cavazzana-Calvo M, Payen E, Negre O, Wang G, Hehir K, Fusil F, Down J, Denaro M, Brady T, Westerman K, Cavallesco R, Gillet-Legrand B, Caccavelli L, Sgarra R, Maouche-Chrétien L, Bernaudin F, Girot R, Dorazio R, Mulder GJ, Polack A, Bank A, Soulier J, Larghero J, Kabbara N, Dalle B, Gourmel B, Socie G, Chrétien S, Cartier N, Aubourg P, Fischer A, Cornetta K, Galacteros F, Beuzard Y, Gluckman E, Bushman F, HaceinBey-Abina $S$ and Leboulch P: Transfusion independence and HMGA2 activation after gene therapy of human $\beta$-thalassaemia. Nature 467: 318-322, 2010.

2. Kaiser J: Gene therapy. Beta-thalassemia treatment succeeds, with a caveat. Science 326: 1468-1469, 2009.

3. Dong A, Rivella S and Breda L: Gene therapy for hemoglobinopathies: progress and challenges. Transl Res 161: 293-306, 2013

4. Breda L, Casu C, Gardenghi S, Bianchi N, Cartegni L, Narla M, Yazdanbakhsh K, Musso M, Manwani D, Little J, Gardner LB, Kleinert DA, Prus E, Fibach E, Grady RW, Giardina PJ Gambari R and Rivella S: Therapeutic hemoglobin levels after gene transfer in $\beta$-thalassemia mice and in hematopoietic cells of $\beta$-thalassemia and sickle cells disease patients. PLoS One 7: e32345, 2012 .

5. Zou J, Mali P, Huang X, Dowey SN and Cheng L: Site-specific gene correction of a point mutation in human iPS cells derived from an adult patient with sickle cell disease. Blood 118: 4599-4608, 2011.

6. Gambari R and Fibach E: Medicinal chemistry of fetal hemoglobin inducers for treatment of beta-thalassemia. Curr Med Chem 14: 199-212, 2007.

7. Reid ME, El Beshlawy A, Inati A, Kutlar A, Abboud MR, Haynes J Jr, Ward R, Sharon B, Taher AT, Smith W, Manwani D and Ghalie RG: A double-blind, placebo-controlled phase II study of the efficacy and safety of 2,2-dimethylbutyrate (HQK-1001), an oral fetal globin inducer, in sickle cell disease. Am J Hematol 89: 709-713, 2014.

8. Perrine SP, Pace BS and Faller DV: Targeted fetal hemoglobin induction for treatment of beta hemoglobinopathies. Hematol Oncol Clin North Am 28: 233-248, 2014.

9. Breda L, Rivella S, Zuccato C and Gambari R: Combining gene therapy and fetal hemoglobin induction for treatment of $\beta$-thalassemia. Expert Rev Hematol 6: 255-264, 2013.

10. Zuccato C, Breda L, Salvatori F, Breveglieri G, Gardenghi S Bianchi N, Brognara E, Lampronti I, Borgatti M, Rivella S and Gambari R: A combined approach for $\beta$-thalassemia based on gene therapy-mediated adult hemoglobin (HbA) production and fetal hemoglobin (HbF) induction. Ann Hematol 91: 1201-1213, 2012.

11. Voit RA, Hendel A, Pruett-Miller SM and Porteus MH: Nucleasemediated gene editing by homologous recombination of the human globin locus. Nucleic Acids Res 42: 1365-1378, 2014.

12. Ma N, Liao B, Zhang H, Wang L, Shan Y, Xue Y, Huang K, Chen S, Zhou X, Chen Y, Pei D and Pan G: Transcription activator-like effector nuclease (TALEN)-mediated gene correction in integration-free $\beta$-thalassemia induced pluripotent stem cells. J Biol Chem 288: 34671-34679, 2013.

13. Salvatori F, Breveglieri G, Zuccato C, Finotti A, Bianchi N, Borgatti M, Feriotto G, Destro F, Canella A, Brognara E, Lampronti I, Breda L, Rivella S and Gambari R: Production of beta-globin and adult hemoglobin following G418 treatment of erythroid precursor cells from homozygous beta039 thalassemia patients. Am J Hematol 84: 720-728, 2009.
14. Ansari SH, Shamsi TS, Ashraf M, Perveen K, Farzana T, Bohray M, Erum S and Mehboob T: Efficacy of hydroxyurea in providing transfusion independence in $\beta$-thalassemia. J Pediatr Hematol Oncol 33: 339-343, 2011.

15. Fibach E, Bianchi N, Borgatti M, Prus E and Gambari R: Mithramycin induces fetal hemoglobin production in normal and thalassemic human erythroid precursor cells. Blood 102: 1276-1281, 2003.

16. Salvador A, Brognara E, Vedaldi D, Castagliuolo I, Brun P, Zuccato C, Lampronti I and Gambari R: Induction of erythroid differentiation and increased globin mRNA production with furocoumarins and their photoproducts. J Photochem Photobiol B 121: 57-66, 2013

17. Fibach E, Bianchi N, Borgatti M, Zuccato C, Finotti A, Lampronti I, Prus E, Mischiati C and Gambari R: Effects of rapamycin on accumulation of alpha-, beta- and gamma-globin mRNAs in erythroid precursor cells from beta-thalassaemia patients. Eur J Haematol 77: 437-441, 2006.

18. Gräslund T, Li X, Magnenat L, Popkov M and Barbas CF III: Exploring strategies for the design of artificial transcription factors: targeting sites proximal to known regulatory regions for the induction of gamma-globin expression and the treatment of sickle cell disease. J Biol Chem 280: 3707-3714, 2005.

19. Wilber A, Tschulena U, Hargrove PW, Kim YS, Persons DA, Barbas CF III and Nienhuis AW: A zinc-finger transcriptional activator designed to interact with the gamma-globin gene promoters enhances fetal hemoglobin production in primary human adult erythroblasts. Blood 115: 3033-3041, 2010.

20. Xu XS, Hong X and Wang G: Induction of endogenous gammaglobin gene expression with decoy oligonucleotide targeting Oct-1 transcription factor consensus sequence. J Hematol Oncol 2: 15, 2009.

21. Gambari R: Alternative options for DNA-based experimental therapy of $\beta$-thalassemia. Expert Opin Biol Ther 12: 443-462, 2012.

22. Sankaran VG, Menne TF, Šćepanović D, Vergilio JA, Ji P, Kim J, Thiru P, Orkin SH, Lander ES and Lodish HF: MicroRNA-15a and -16-1 act via MYB to elevate fetal hemoglobin expression in human trisomy 13. Proc Natl Acad Sci USA 108: 1519-1524, 2001.

23. Lulli V, Romania P, Morsilli O, Cianciulli P, Gabbianelli M, Testa U, Giuliani A and Marziali G: MicroRNA-486-3p regulates $\gamma$-globin expression in human erythroid cells by directly modulating BCL11A. PLoS One 8: e60436, 2013.

24. Ma Y, Wang B, Jiang F, Wang D, Liu H, Yan Y, Dong H, Wang F, Gong B, Zhu Y, Dong L, Yin H, Zhang Z, Zhao H, Wu Z, Zhang J, Zhou J and Yu J: A feedback loop consisting of microRNA $23 \mathrm{a} / 27 \mathrm{a}$ and the $\beta$-like globin suppressors KLF3 and SP1 regulates globin gene expression. Mol Cell Biol 33: 3994-4007, 2013.

25. Kaul DK, Fabry ME and Nagel RL: The pathophysiology of vascular obstruction in the sickle syndromes. Blood Rev 10: 29-44, 1996.

26. Rodgers GP: Overview of pathophysiology and rationale for treatment of sickle cell anemia. Semin Hematol 34: 2-7, 1997.

27. Vekilov PG: Sickle-cell haemoglobin polymerization: is it the primary pathogenic event of sickle-cell anaemia? Br J Haematol 139: 173-184, 2007.

28. Vasseur C, Pissard S, Domingues-Hamdi E, Marden MC, Galactéros F and Baudin-Creuza V: Evaluation of the free $\alpha$-hemoglobin pool in red blood cells: a new test providing a scale of $\beta$-thalassemia severity. Am J Hematol 86: 199-202, 2011.

29. Rivella S: Do not super-excess me! Blood 119: 5064-5065, 2012.

30. Kassim AA and DeBaun MR: Sickle cell disease, vasculopathy, and therapeutics. Annu Rev Med 64: 451-466, 2013.

31. Raghupathy R and Billett HH: Promising therapies in sickle cell disease. Cardiovasc Hematol Disord Drug Targets 9: 1-8, 2009.

32. Steinberg MH: Pathophysiologically based drug treatment of sickle cell disease. Trends Pharmacol Sci 27: 204-210, 2006.

33. Gambari R: Peptide nucleic acids: a review on recent patents and technology transfer. Expert Opin Ther Pat 24: 267-294, 2014.

34. Nielsen PE, Egholm M, Berg RH and Buchardt O: Sequenceselective recognition of DNA by strand displacement with a thymine-substituted polyamide. Science 254: 1497-1500, 1991.

35. Egholm M, Buchardt O, Christensen L, Behrens C, Freier SM, Driver DA, Berg RH, Kim SK, Norden B and Nielsen PE: PNA hybridizes to complementary oligonucleotides obeying the Watson-Crick hydrogen-bonding rules. Nature 365: 566-568, 1993.

36. Gambari R: Peptide-nucleic acids (PNAs): a tool for the development of gene expression modifiers. Curr Pharm Des 7: 1839-1862, 2001. 
37. Gambari R, Terada M, Bank A, Rifkind RA and Marks PA: Synthesis of globin mRNA in relation to the cell cycle during induced murine erythroleukemia differentiation. Proc Natl Acad Sci USA 75: 3801-3804, 1978.

38. Gambari R, Marks PA and Rifkind RA: Murine erythroleukemia cell differentiation: relationship of globin gene expression and of prolongation of G1 to inducer effects during G1/early S. Proc Natl Acad Sci USA 76: 4511-4515, 1979.

39. Rutherford TR and Harrison PR: Globin synthesis and erythroid differentiation in a Friend cell variant deficient in heme synthesis. Proc Natl Acad Sci USA 76: 5660-5664, 1979.

40. Salvatori F, Cantale V, Breveglieri G, Zuccato C, Finotti A, Bianchi N, Borgatti M, Feriotto G, Destro F, Canella A, Breda L, Rivella S and Gambari R: Development of K562 cell clones expressing beta-globin mRNA carrying the beta039 thalassaemia mutation for the screening of correctors of stop-codon mutations. Biotechnol Appl Biochem 54: 41-52, 2009.

41. Fabbri E, Manicardi A, Tedeschi T, Sforza S, Bianchi N, Brognara E, Finotti A, Breveglieri G, Borgatti M, Corradini R, Marchelli R and Gambari R: Modulation of the biological activity of microRNA-210 with peptide nucleic acids (PNAs). ChemMedChem 6: 2192-2202, 2011.

42. Nastruzzi C, Cortesi R, Esposito E, Gambari R, Borgatti M, Bianchi N, Feriotto G and Mischiati C: Liposomes as carriers for DNA-PNA hybrids. J Control Release 68: 237-249, 2000.
43. Borgatti M, Breda L, Cortesi R, Nastruzzi C, Romanelli A, Saviano M, Bianchi N, Mischiati C, Pedone C and Gambari R: Cationic liposomes as delivery systems for double-stranded PNA-DNA chimeras exhibiting decoy activity against NF-kappaB transcription factors. Biochem Pharmacol 64: 609-616, 2002.

44. Brognara E, Fabbri E, Bianchi N, Finotti A, Corradini R and Gambari R: Molecular methods for validation of the biological activity of peptide nucleic acids targeting microRNAs. Methods Mol Biol 1095: 165-176, 2014.

45. Brognara E, Fabbri E, Aimi F, Manicardi A, Bianchi N, Finotti A, Breveglieri G, Borgatti M, Corradini R, Marchelli R and Gambari R: Peptide nucleic acids targeting miR-221 modulate p2 $7^{\mathrm{Kip} 1}$ expression in breast cancer MDA-MB-231 cells. Int J Oncol 41: 2119-2127, 2012.

46. Bhatnagar P, Keefer JR, Casella JF, Barron-Casella EA, Bean CJ, Hooper CW, Payne AB, Arking DE and Debaun MR: Association between baseline fetal hemoglobin levels and incidence of severe vaso-occlusive pain episodes in children with sickle cell anemia. Pediatr Blood Cancer 60: E125-E127, 2013.

47. Rodrigue CM, Arous N, Bachir D, Smith-Ravin J, Romeo PH, Galacteros F and Garel MC: Resveratrol, a natural dietary phytoalexin, possesses similar properties to hydroxyurea towards erythroid differentiation. Br J Haematol 113: 500-507, 2001. 